\title{
Relações entre práticas educativas parentais e rendimento acadêmico em crianças
}

\author{
Caroline Guisantes de Salvo Toni - Universidade Estadual do Centro-Oeste, Irati, Brasil \\ Vanessa Aparecida Hecaveí - Universidade Estadual do Centro-Oeste, Irati, Brasil
}

\begin{abstract}
Resumo
As práticas educativas parentais são as formas utilizadas pelos pais para contingenciar o comportamento dos filhos. Dessa perspectiva, o objetivo deste estudo foi analisar a correlação entre estilos parentais e desempenho acadêmico; assim, as notas escolares das crianças nas disciplinas de matemática e português foram registradas. Participaram deste estudo 203 crianças com idade entre oito e onze anos, de ambos os sexos, que cursavam entre $3^{\circ}$ e $5^{\circ}$ ano de duas escolas municipais localizadas no interior do Paraná. Os participantes responderam ao Inventário de Estilos Parentais. Foram encontradas correlações entre as práticas educativas e o rendimento acadêmico, em especial com as práticas maternas. Foram observadas diferenças significativas nas médias das práticas educativas e estilos parentais referenciadas por estudantes com alto e baixo rendimento escolar. As práticas educativas maternas e paternas foram consideradas preditoras do rendimento acadêmico. Discute-se a importância das práticas parentais, em especial as maternas, no desenvolvimento acadêmico de crianças.

Palavras-chaves: Interação pais-filhos; Rendimento escolar; Desenvolvimento infantil.
\end{abstract}

\section{Relationship between parental practices and academic performance in children}

\begin{abstract}
The parenting practices are the forms used by parents to impound their children's behavior. From this perspective, the goal of this study was to analyze how parenting styles and children's academic achievement relate to one other; thus, all children's school grades in the subjects of Mathematics and Portuguese were recorded. Study participants were 203 children aged between eight and eleven years old, of both sexes, who were enrolled between third and fifth year from two public schools in the interior of Paraná, Brazil. Participants responded to Parenting Styles Inventory. Correlations were found between education and academic performance, especially with maternal practices. Significant differences were observed in mean parenting practices and parenting styles referenced by students with high and low academic performance. The maternal and Discusses the importance of parenting, especially the maternal in academic development of children.

Keywords: Parent-child interaction; School performance; Child development.
\end{abstract}

Relación entre las prácticas educativas parental y el rendimiento académico en los niños

\section{Resumen}

Las prácticas educativas parentales son las formas utilizadas por los padres para confiscar el comportamiento de los hijos. A partir de esa perspectiva, la búsqueda de verificar las relaciones entre las prácticas educativas paternales y el rendimiento académico, expresos por la media escolar en las disciplinas de portugués y matemáticas, de chicos. Participaron de ese estudio 203 chicos con edad entre ocho y once años, de ambos los sexos, que cursaban entre $3^{\circ}$ y $5^{\circ}$ año de dos escuelas municipales del interior de Paraná, Brasil. Los participantes contestaron al Inventario de Estilos Parentales. Fueron encontradas correlaciones entre las prácticas educativas y el rendimiento académico. Fueron observadas diferencias significativas en las medias de las prácticas educativas referenciadas por estudiantes con alto y bajo rendimiento escolar. Las prácticas educativas fueron consideradas predictores del rendimiento académico. Se habla la importancia de las prácticas parentales, en especial las maternales, en el desarrollo académico de chicos.

Palabras-clave: Relaciones padres-hijo; Rendimiento escolar; Desarrollo infantil.

\section{Introdução}

O desenvolvimento da criança e do adolescente é afetado por diversos fatores, incluindo desde as questões relativas ao seu desenvolvimento orgânico (fatores teratogênicos e genéticos), até aqueles de ordem social e cultural, que se manifestam, por exemplo, a partir da família, escola e comunidade. Nesse cenário, os pais têm destaque, uma vez que esses são o primeiro contexto a exercer controle sobre o comportamento da criança. As estratégias utilizadas como formas de educar, instruir, socializar e controlar o comportamento dos filhos são denominadas de práticas educativas parentais (Alvarenga \& Piccinini, 2001); ao conjunto dessas práticas educativas, que podem ser utilizadas em intensidade e frequências variadas, denomina-se de estilos parentais (Gomide, 2003).

Alguns autores, como Gomide (2003), diferenciam práticas educativas parentais em positivas e negativas. As práticas positivas transmitem confiança, amor e carinho, colaborando para o desenvolvimento de comportamentos prossociais; já as práticas negativas tendem a ser geradoras de conflitos entre pais e filhos, desencadeiam estresse, desconfiança, abusos 
físicos, e podem levar a comportamentos antissociais. As práticas descritas por Gomide (2004) são sete, que se dividem em positivas e negativas. As práticas positivas seriam a monitoria positiva e o comportamento moral, e as práticas negativas, o abuso físico, a punição inconsistente, disciplina relaxada, monitoria negativa e a negligência.

A prática educativa positiva da monitoria positiva pode ser definida como um conjunto de ações que envolvem afeto, acompanhamento e atenção dos pais em relação ao seu filho; já a prática educativa do comportamento moral pode ser compreendida como a transmissão de valores como justiça, generosidade, honestidade, entre outros, a partir do modelo de comportamento dado pelos pais para a criança, contribuindo para que esta discrimine comportamentos considerados certos e errados, a partir dos valores culturais da família (Gomide, 2003; 2004).

Dentre as práticas educativas negativas, têm-se o abuso físico, que pode ser definido como práticas de punição administradas pelos pais e que ferem a criança. A disciplina relaxada descreveria práticas em que os pais estabelecem regras para seus filhos, porém não as cumprem. A monitoria negativa ou supervisão estressante pode ser definida pelas ações de controle e fiscalização dos pais sobre o comportamento dos filhos, caracterizadas principalmente pela exagerada vigilância e pelas instruções repetitivas. A negligência se caracteriza pela ausência e/ ou pela falta de amor dos pais e a punição inconsistente, por práticas educativas que ocorrem a partir do locus de controle do humor dos pais, ou seja, o estado emocional dos pais é o fator determinante das ações educativas e não as ações da criança (Gomide, 2003; 2004).

A influência das práticas educativas parentais sobre o comportamento de crianças e adolescentes tem sido vastamente descrita. Exemplo disso são as pesquisas que demonstram a associação entre práticas parentais positivas e habilidades sociais em crianças e adolescentes, bem como entre práticas negativas e problemas de comportamento (Ceconello, Antoni \& Koller, 2003; Cia, Pamplin \& Del Prette, 2006; Pereira \& Del Prette, 2006; Martinho, 2010; Sabbag \& Bolsoni-Silva, 2010). Outras pesquisas (Alvarenga \& Piccinini 2007; Benetti, Pizetta, Schwartz, Hass \& Melo, 2010; Boas \& Bolsoni-Silva, 2010; Pereira, Santos \& Williams, 2009; Reppold \& Hutz, 2003; Salvo, Silvares \& Toni, 2005; Sousa, 2010; Stattin \& Kerr, 2000; Zamberlan, Ottoni \& Sônego, 2005) fazem referência a correlações entre estilo parental e características dos filhos, buscando descrever como as práticas parentais são capazes de predizer os problemas de comportamento de crianças.
Ainda nessa linha de estudos, outras pesquisas (Antunes, 2010; Beato, 2008; Boecke \& Sarriera, 2006; Bolsoni-Silva, 2010; Bolsoni-Silva \& Marturano, 2010; Lila, 2009; Loss \& Cassemiro, 2010; Moreira \& Biasoli-Alves, 2008; Salvo \& cols., 2005; Sousa, 2010; Weber, Brandenburg \& Viezzer, 2003; Weber, Brandenburg \& Viezzer, 2004) destacam as correlações positivas entre as práticas parentais e características da criança e do adolescente, como nível de otimismo, competência social, valores, entre outras. A monitoria positiva e o comportamento moral são ainda considerados preditores de competência social em adolescentes (Salvo \& cols., 2005) e preditores de ajustamento social em crianças (Stattin \& Kerr, 2000).

Estudos (Loos \& Cassemiro, 2010; Beato \& Narciso, 2008) relatam ainda associação entre as práticas de suporte emocional e a presença de ligações mais seguras dos filhos em relação aos pais e pares; relatam, também, que filhos com pais de estilo parental autoritativo (aqueles com altas práticas educativas envolvendo acompanhamento e regras) apresentam escores mais elevados de bem-estar psicológico (Boeckel \& Sarriera, 2006). Escores mais elevados de autoestima relatados pela criança se relacionaram positivamente à percepção de práticas parentais de suporte no progenitor do sexo oposto (Lila, 2009). Os pais negligentes foram associados a menores escores de otimismo e a maiores escores de passividade (Weber \& cols., 2003), bem como pais notificados pelo Estado por abusar fisicamente de seus filhos descreveram seus filhos como crianças mais difíceis e com mais dificuldades de comportamento, podendo indicar um ciclo de retroalimentação do comportamento disruptivo entre as práticas parentais e o comportamento da criança (Bérgamo \& Bazon, 2011).

A forte relação entre o estilo parental, práticas educativas e comportamentos de crianças e adolescentes apresenta base empírica de suporte. Porém, será que esta mesma relação ocorre entre as práticas educativas parentais e o desempenho acadêmico de crianças? Tal pergunta se mostra pertinente, uma vez que ao se entender a família como um contexto de grandes reforçadores na infância e o desempenho acadêmico como uma classe de respostas multideterminada, afetada por diversas condições culturais, familiares, socioeconômicas, comunitárias e escolares, é possível supor que as práticas educativas parentais exerçam algum controle sobre essa classe de comportamentos.

Diversos estudos foram encontrados demonstrando relações entre essas variáveis. $O$ estudo de Sapienza, Aznar-Farias e Silvares (2009) teve como 
objetivo investigar as relações entre competência social, práticas educativas parentais e rendimento acadêmico em adolescentes. Desse estudo participaram 66 adolescentes de ambos os sexos, com idade entre 11 e 15 anos, além de seus cuidadores. Aos comparar o grupo de alto rendimento com o de baixo rendimento acadêmico, observou-se que adolescentes com alto rendimento acadêmico tinham pais com mais práticas educativas positivas e também eram vistos por seus pais como mais competentes socialmente. Ainda, observou correlações mais fortes entre as práticas educativas maternas e o desempenho acadêmico. Esse estudo demonstrou haver diferenças nas práticas de pais de crianças com rendimentos acadêmicos diferentes, porém, não teve como objetivo avaliar o quanto cada prática educativa parental poderia predizer o rendimento acadêmico.

A pesquisa realizada por Garcia, Brino e Willians (2009) buscou ampliar o conhecimento sobre fatores de risco e de resiliência envolvidos no desenvolvimento da criança, tendo como objetivo identificar esses fatores entre escolares provenientes de famílias menos favorecidas economicamente. Participaram do estudo 107 crianças de $3^{\text {as }}$ e $4^{\text {as }}$ séries, com idade entre 10 a 13 anos. Do total de participantes, $28,57 \%$ das crianças apresentaram baixo rendimento acadêmico. Desse grupo, quase metade das mães (46\%) relatou que seus filhos apresentavam alto índice de problemas emocionais/ comportamentais. Os resultados indicaram que, para esse grupo, os estilos e as condutas parentais eram significativamente mais negativos e o rendimento acadêmico era inferior quando comparado ao grupo com menos problemas.

Sobre a relação pai-filho e desenvolvimento acadêmico, alguns autores descrevem a relação entre $\mathrm{O}$ envolvimento paterno no desenvolvimento acadêmico dos filhos. É o que o estudo de Cia, D'Affonseca e Barham (2004) se propôs ao avaliar o impacto da qualidade do relacionamento pai-filho sobre o desempenho acadêmico de crianças. A pesquisa realizou-se com 58 pais, o teve como resultados que, quanto maior o envolvimento e a frequência de relação e comunicação entre pais-filhos, melhor foi o desempenho acadêmico da criança. Estudo de Mcbride, Schoppe-Sullivan e Ho (2005), com 1.334 famílias, buscou relacionar o envolvimento paterno na mediação da aprendizagem das crianças. Os autores apontam que há uma relação significativa do envolvimento paterno no desenvolvimento acadêmico, e que este envolvimento media a relação entre escola, família e comunidade. Ou seja, o acompanhamento, ou ao menos a ausência de negligência, parece colaborar para um bom desempenho acadêmico.
Estudo de Cia, Pamplin e Williams (2008) com 110 crianças da $4^{a}$ série do Ensino Fundamental, com idade média de 10 anos, observou que quanto maior a frequência da participação de ambos os pais nas atividades escolares e a comunicação entre pais-filhos, melhor foi o desempenho escolar das crianças no que diz respeito à leitura, escrita e aritmética, tal qual outros estudos (Garcia \& cols., 2009). Os resultados do estudo correlacional de Camacho e Matos (2007) encontrou associações positivas entre as práticas parentais relacionadas a carinho e autonomia e rendimento acadêmico; também observou correlações inversamente proporcionais entre excessiva fiscalização e proteção e rendimento acadêmico. Ainda, o estudo de Costa, Cia e Barham (2007) comparou famílias monoparentais e famílias nucleares quanto à qualidade da relação mãe-filho e o desempenho acadêmico (DA). Os resultados apontaram correlações positivas entre a relação com a mãe e o DA, em especial nas famílias monoparentais.

Estudo de Cia, Barham e Fontaine (2008) buscou avaliar o impacto de um grupo de orientação a pais sobre o repertório social e o desempenho acadêmico de crianças. Os resultados demonstraram diferenças significativas do pré para o pós-teste nas habilidades de leitura e índice de habilidades sociais das crianças, cujos pais haviam participado da intervenção. As autoras sugerem que a melhora no acompanhamento dos pais das atividades escolares pode ter sido associada à melhora na leitura.

Estudos de Salvador $(2007$; 2012) buscaram avaliar a relação das práticas educativas parentais e o envolvimento com tarefas escolares, depressão e desempenho acadêmico em adolescentes, bem como o efeito de grupos de orientação a pais sobre o desempenho acadêmico da criança. Os resultados indicaram correlações positivas entre práticas educativas positivas, envolvimento nas tarefas escolares e desempenho acadêmico, sendo estes resultados inversamente correlacionados a depressão.

Com base nessas considerações, o objetivo geral do presente estudo foi avaliar se as práticas educativas parentais exercem influência direta sobre o rendimento escolar, uma vez que os estudos encontrados na literatura descrevem influências indiretas, ou seja, relacionais e correlacionais entre práticas educativas e rendimento acadêmico. Tem ainda, como objetivos secundários, correlacionar práticas educativas parentais e rendimento escolar e comparar se estas são diferentes entre crianças com alto rendimento escolar e baixo rendimento escolar. 


\section{Método}

\section{Participantes:}

Participaram 203 alunos, de ambos os sexos, cursando 1 turma de 2 série $(\mathrm{N}=20), 3$ turmas de 3 série $(\mathrm{N}=72)$ e 5 turmas de 4 série $(\mathrm{N}=111)$ do ensino fundamental de duas escolas públicas de um município de médio porte do interior do Estado do Paraná. A idade variou de 8 a 11 anos, sendo a média de 9,5 anos, com desvio padrão de 0,8 anos.

\section{Materiais e Instrumentos:}

Inventário de Estilos Parentais - IEP (Gomide, 2006). O IEP é composto por sete escalas que avaliam duas práticas educativas positivas (monitoria positiva e comportamento moral) e cinco negativas (disciplina relaxada, monitoria negativa, negligência, punição inconsistente e abuso físico), cada uma delas com seis itens em escala Likert de três pontos, sendo $0=$ nunca, $1=$ as vezes e $2=$ sempre. $O$ avaliando avalia a frequência com que seu pai, mãe ou cuidador utiliza a prática descrita no item e assinala a escala. $O$ índice de cada prática educativa é calculado através do somatório simples dos seis itens da escala e o índice de Estilo Parental é encontrado somando-se os pontos obtidos nas escalas das práticas positivas que são subtraídos do somatório dos pontos das cinco escalas das práticas negativas. O índice quando negativo informa a prevalência de práticas educativas negativas e quando positivo, a prevalência de práticas positivas no processo educacional.

Notas Escolares - Medida de Rendimento Acadêmico. As notas foram fornecidas pela coordenação pedagógica da escola. A partir destas, os alunos foram divididos em três grupos em razão de seu rendimento nas disciplinas de língua portuguesa e matemática, sendo tal rendimento estabelecido a partir dos conceitos obtidos nas disciplinas do segundo bimestre do ano letivo em que ocorreu a coleta de dados.

Procedimento de coleta de dados. A coleta foi realizada em duas escolas, sendo cinco turmas em uma escola e quatro turmas em outra. A aplicação do instrumento ocorreu de forma coletiva no horário de aula. A duração média de cada uma das aplicações foi de cinquenta minutos. As crianças foram instruídas a responderem o inventário de estilos parentais sobre a mãe e sobre o pai. No caso da criança morar com outros cuidadores, orientada a responder ao inventário tomando como base a forma como esses cuidadores agiam com ela. $\mathrm{Na}$ inexistência de um dos pais ou cuidador (por exemplo, o pai ou alguém que representasse essa figura no contexto), a criança não precisaria responder ao inventário que descrevia sua relação com essa figura. Inicialmente, os aplicadores leram em voz alta as instruções para o preenchimento do instrumento, informando aos alunos que poderiam esclarecer quaisquer dúvidas durante a aplicação. No decorrer das aplicações os pesquisadores permaneceram à disposição dos alunos, sendo que aqueles que relataram dificuldades na leitura e/ ou compreensão do instrumento tiveram auxílio individual para seu preenchimento.

Tratamento e análise dos dados. Os escores de cada prática educativa materna e paterna, bem como o índice de estilo parental final do pai e da mãe, juntamente com as notas escolares, foram computados no Programa SPSS 18.0.

A partir da base de dados, calculou-se o valor do rendimento acadêmico de cada aluno; para tanto foi feita uma média simples das notas bimestrais das disciplinas de português e matemática. A partir do índice de rendimento acadêmico dos participantes, foram obtidos os quartis dos valores de rendimento, de modo que tais valores foram divididos em quatro intervalos: um com $25 \%$ dos valores mais baixos, dois intervalos formados por $25 \%$ dos valores intermediários e um intervalo com $25 \%$ dos valores de desempenho mais altos. Dessa forma, o critério para a classificação em um dos três grupos de rendimento foi o intervalo em que o valor de rendimento acadêmico do aluno se encontrava. No primeiro quartil, correspondente ao valor de rendimento menor ou igual a 64,25 , foram classificados os alunos com rendimento acadêmico baixo $(\mathrm{N}=49)$. No segundo e no terceiro quartis, correspondentes aos valores de rendimento entre 64,5 e 84,75 , foram classificados os alunos com rendimento acadêmico médio $(\mathrm{N}=106)$, e no quarto quartil, correspondente ao valor de rendimento acima de 85 , foram classificados os alunos com rendimento acadêmico alto $(\mathrm{N}=51)$. A partir da construção do índice de rendimento acadêmico e da construção dos grupos, passaram-se às análises inferenciais.

A primeira etapa envolveu análise de correlação de Pearson entre o rendimento acadêmico e os escores das práticas educativas e estilos parentais. $\mathrm{Na}$ segunda etapa, as médias de cada uma das práticas educativas dos grupos de alto e baixo rendimento acadêmico foram comparadas por meio da realização do teste $\mathrm{T}$ de Student, no qual se considerou um nível de significância estatística de $p<0,05$. Para finalizar a análise, procedeu-se a uma análise multivariada, a partir de modelos de regressão múltipla (stepwise). O teste de 
correlação de Pearson avalia a relação entre duas variáveis, porém não detecta o sentido da influência, sendo assim, é necessária à utilização de análise multivariada para compreender o efeito de uma variável sobre outra. Para examinar o efeito exercido por duas ou mais variáveis independentes sobre uma variável dependente é comum a utilização de análise de regressão múltipla. A regressão múltipla (RM) é um conjunto de técnicas estatísticas que avalia a relação de uma variável dependente (VD) com diversas variáveis independentes (VI), ou seja, a influência diretamente observada de uma ou mais variáveis independentes sobre a variável dependente (Hair, Anderson, Tatham \& Black, 2005). No presente estudo, as práticas educativas foram tomadas como VI e o rendimento escolar a VD.

\section{Resultados e Discussão}

$\mathrm{Na}$ Tabela 1, estão apresentadas as correlações entre a média do rendimento acadêmico e as práticas educativas paternas e maternas, além da correlação com o estilo parental.

Pode-se observar, a partir da Tabela 1, que, em sua maioria, as práticas educativas maternas se correlacionam com a média escolar. As práticas educativas de monitoria positiva e comportamento moral apresentaram relações positivas e moderadas com a média escolar, indicando que crianças que apresentam altas médias relatam também perceber sua mãe com alto nível de acompanhamento, afeto e valores morais. Também, a média de rendimento acadêmico se correlacionou de forma negativa e significativa com as práticas de punição inconsistente, disciplina relaxada, negligência e abuso físico; vale destacar o índice de correlação moderado e inversamente proporcional observado entre abuso físico e o rendimento acadêmico. Diversos estudos (Garcia \& cols., 2009; Salvador, 2007; Sapienza \& cols., 2009) apontam que o bom desempenho acadêmico está ligado a famílias mais envolvidas, que acompanham a criança, monitorando suas atividades; também, apontam relações entre o mau desempenho acadêmico e mães e pais que utilizam práticas negativas, destacando-se a relação entre punição física e notas baixas.

Observou-se uma maior associação entre as práticas maternas e rendimento acadêmico do que associações entre as práticas paternas e a mesma variável. Tais resultados podem estar relacionados à maior proximidade da mãe com o filho nessa fase do desenvolvimento, do final da infância e início da adolescência.
Tabela 1. Correlação das práticas parentais e rendimento acadêmico

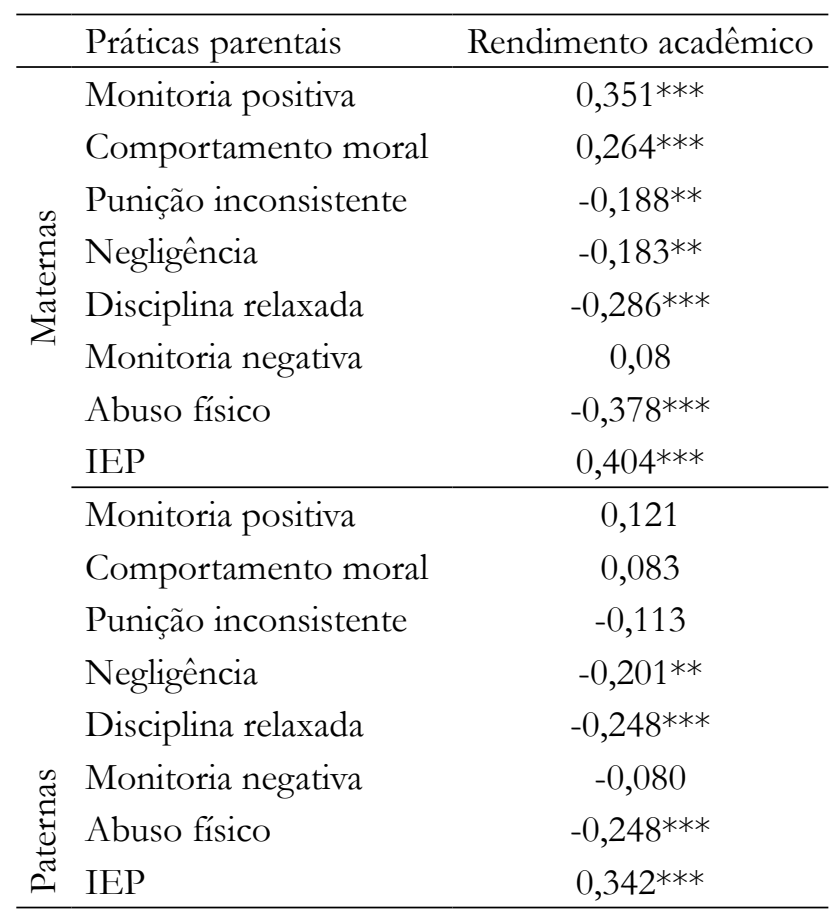

${ }^{*} \mathrm{p} \leq 0,05 ;{ }^{*} \mathrm{p} \leq 0,01 ; * * \mathrm{p} \leq 0,001$.

Estudos (Cia \& cols., 2006; Moreira \& Biasoli-Alves, 2008; Zamberlan \& cols., 2005) observaram que a relação da mãe com a criança nesse período de desenvolvimento é mais forte do que com o pai, visto que cabe à mãe, em geral, a rotina diária de banho, hora de dormir, refeições e outros afazeres, como tarefas escolares. Em média, as atividades do lar são realizadas em conjunto mãe-filho, o que poderia explicar a maior frequência de correlações observadas entre práticas maternas e desempenho acadêmico.

Quanto à percepção do comportamento do pai, houve correlações significativas apenas entre algumas práticas educativas negativas e a média escolar, sendo em geral correlações de baixa intensidade. Houve associações significativas do ponto de vista estatístico entre rendimento acadêmico e negligência, disciplina relaxada e abuso físico, porém todas com índices de correlação inferiores aos observados nas práticas maternas. Destacam-se, novamente, os índices de correlação negativa entre média escolar e as práticas de abuso físico e disciplina relaxada, também observada na relação com o comportamento materno, indicando, outra vez, uma possível associação entre essas variáveis. Estudos (Cia \& cols., 2004; Cia \& cols., 2008; Mcbride \& cols., 2005; 
Salvador, 2007) que avaliaram o envolvimento paterno e o desempenho acadêmico de crianças observaram que, quanto maior a frequência da comunicação e afeto entre pai e filho e quanto maior o envolvimento dos pais nas atividades do filho, melhor o desempenho acadêmico das crianças. Ainda, estudos (Cia \& cols., 2006; Salvador, 2007; Salvo, 2010; Sapienza \& cols., 2009) demonstram que, na opinião dos filhos, quando comparados mães e pais, as crianças relatam que os pais utilizam mais práticas educativas negativas, principalmente abuso físico.

O estilo parental é avaliado a partir das sete práticas educativas, e este expressa a relação (frequência e intensidade) do uso de práticas positivas e negativas pelos pais. Tanto o estilo parental materno, quanto o paterno mostraram-se significativamente correlacionados ao rendimento acadêmico, sendo que o estilo parental materno teve um índice um pouco mais elevado de correlação. De forma geral, estudos (Cia \& cols. 2004; Cia \& cols., 2008; Garcia \& cols., 2009; Salvo, 2010; Sapienza \& cols., 2009) apontam a importância tanto do envolvimento materno quanto paterno para o desempenho escolar. As correlações positivas observadas entre o estilo parental materno, paterno e o rendimento acadêmico são um resultado esperado, pois se os pais apresentam uma boa relação com seus filhos, possuem em maior frequência e intensidade práticas educativas positivas e propiciam um ambiente familiar confiável e afetivo ao filho, este tende a desenvolver autoestima e autoconfiança elevadas, além de possuir habilidades que contribuem para a aprendizagem (como as habilidades sociais) e consequentemente, para os resultados acadêmicos favoráveis.

Buscando comparar o estilo parental e práticas educativas das mães e pais das crianças com alto e baixo rendimento acadêmico, construiu-se a Tabela 2 . Nesta estão apresentados os valores da comparação dos dois grupos a partir do teste T de Student.

Pode-se observar através da Tabela 2, que, com exceção da prática educativa monitoria negativa, em todas as outras os dois grupos apresentam diferenças significativas. Em todos os casos, as crianças com alto rendimento escolar relatam mães com maiores níveis de práticas positivas e menor índice de práticas negativas do que as crianças com baixo rendimento acadêmico. Isso vai em direção a vários estudos (Bolsoni-Silva \& Marturano, 2007; Cia \& cols., 2004; Cia \& cols., 2008; Costa \& cols, 2007; Pereira \& cols., 2009; Sapienza \& cols., 2009; Zamberlan \& cols., 2005) que indicaram relações entre estilo parental positivo e bom desempenho

Tabela 2. Comparação das médias das práticas educativas maternas de criança com alto e baixo rendimento acadêmico

\begin{tabular}{|c|c|c|c|c|c|c|}
\hline \multirow{10}{*}{ 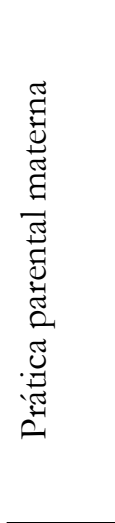 } & & \multicolumn{2}{|c|}{ Alto rendimento } & \multicolumn{2}{|c|}{ Baixo rendimento } & \multirow[t]{2}{*}{ t-Student } \\
\hline & & Média & $\mathrm{Dp}$ & Média & $\mathrm{Dp}$ & \\
\hline & Monitoria positiva & 10,77 & 1,67 & 8,67 & 2,55 & $4,95^{* * *}$ \\
\hline & Comportamento moral & 9,98 & 2 & 8,33 & 2,4 & $3,78^{* * *}$ \\
\hline & Punição inconsistente & 4,21 & 2,21 & 5,02 & 2,06 & $-1,91 *$ \\
\hline & Negligência & 3,06 & 2,48 & 4,31 & 2,23 & $-2,66 * *$ \\
\hline & Disciplina relaxada & 3,51 & 2,05 & 5,04 & 2,61 & $-3,03 * * *$ \\
\hline & Monitoria negativa & 6,11 & 2,09 & 5,86 & 2,46 & 0,567 \\
\hline & Abuso físico & 2,19 & 1,87 & 4,37 & 2,92 & $-4,52 * * *$ \\
\hline & IEP & 1,74 & 9,02 & $-7,73$ & 9,38 & $5,19 * * *$ \\
\hline \multirow{8}{*}{ 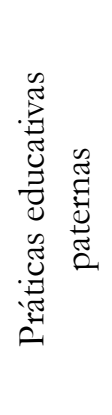 } & Monitoria positiva & 9,47 & 2.83 & 8,51 & 3,02 & 1,63 \\
\hline & Comportamento moral & 8,76 & 3,36 & 8,18 & 2,9 & 0,93 \\
\hline & Punição inconsistente & 3,31 & 2,15 & 3,69 & 2,09 & $-0,89$ \\
\hline & Negligência & 2,76 & 2,47 & 4,29 & 2,29 & $-3,18^{*}$ \\
\hline & Disciplina relaxada & 3,57 & 2,14 & 4,86 & 2,36 & $-2,85$ \\
\hline & Monitoria negativa & 4,88 & 2,62 & 5,49 & 2,39 & $-1,20$ \\
\hline & Abuso físico & 2,31 & 2,23 & 3,69 & 2,83 & $-2,71 *$ \\
\hline & IEP & 1,17 & 7,23 & $-5,24$ & 9,65 & $4,08 * * *$ \\
\hline
\end{tabular}

${ }^{*} \mathrm{p} \leq 0,05 ;{ }^{*} \mathrm{p} \leq 0,01 ; * * * \mathrm{p} \leq 0,001$ 
acadêmico. Também se pode destacar a elevada diferença nas práticas educativas positivas utilizadas pelas mães de crianças com alto rendimento, que segundo dados normativos do IEP (Gomide, 2006), seriam consideradas acima da média. Diversos estudos (Boas \& Bolsoni-Silva, 2010; Camacho \& Matos; 2007; Loss \& Cassemiro, 2010; Martinho, 2010; Salvo \& cols., 2005) descrevem que a monitoria positiva, relacionada ao acompanhamento afetuoso, e o comportamento moral, que colabora para o desenvolvimento de repertórios de responsabilidade e valores éticos, estão relacionados ao desenvolvimento acadêmico, visto que, para um bom desempenho, são necessários comportamentos de estudo e disciplina, que precisam ser desenvolvidos pela criança, com auxílio dos pais. Em relação às práticas educativas negativas, as crianças com baixo desempenho relataram pais com índices mais elevados dessas práticas. Muitos autores (Alvarenga \& Piccinini 2007; Salvador, 2007; Salvo \& cols., 2005) descrevem que disciplinas coercitivas e práticas negativas utilizadas pelos pais levam a comportamentos agressivos dos filhos, problemas de internalização e externalização, bem como problemas escolares. A negligência e falta de acompanhamento adequado dos pais pode levar a insegurança e sentimentos de baixa autoeficácia na criança, o que colabora para o desenvolvimento de outros problemas de comportamento e dificuldades escolares; sem habilidades sociais para resolver problemas, solicitar ajudar e expressar pensamentos e sentimentos, a criança pode isolar-se e deixar de buscar ajuda para suas dificuldades.

Observa-se que apenas a monitoria negativa materna não apresentou diferença significativa entre o grupo de alto e baixo rendimento acadêmico. Essa prática, segundo Gomide (2006), descreve o excesso de fiscalização da vida dos filhos e a grande quantidade de instruções repetitivas, que não são seguidas pela criança. Segundo a autora, essa prática pode ser confundida como algo positivo aos olhos dos pais e da criança, pois é confundida, culturalmente, como uma forma de acompanhamento saudável e de preocupação com o filho. Essa é uma prática geralmente utilizada tanto por famílias com estilos parentais positivos como negativos (Salvo, 2010); daí a possível não discriminação dessa variável do comportamento das mães na comparação entre os grupos.

Ainda em relação à Tabela 2, diferentemente do observado em relação ao comportamento das mães, há poucas diferenças significativas nas práticas educativas paternas das crianças com alto e baixo rendimento acadêmico. Nenhuma prática educativa positiva apresentou diferença significativa, e entre as práticas negativas, observaram-se diferenças nas práticas de negligencia, disciplina relaxada e abuso físico. Diante dos resultados expostos, observa-se que a principal diferença quanto às práticas paternas das crianças com alto $\mathrm{e}$ baixo rendimento escolar é que os pais das crianças com alto rendimento apresentam menor uso de práticas negativas, ao passo que os pais das crianças com baixo rendimento apresentam-se mais negligentes, com menos disciplina e mais abuso físico.

Esses dados vão ao encontro de resultados de outros estudos (Cia \& cols., 2004; McBride \& cols., 2005; Sapienza \& cols., 2009) que observaram diferenças entre as práticas educativas dos pais de crianças com alto e baixo rendimento acadêmico. As pesquisas demonstraram que o acompanhamento, comunicação positiva, baixa negligência e uso de regras consistentes colaboravam para um adequado desenvolvimento escolar da criança. Essas características parentais são fatores protetores no desenvolvimento da criança, pois aumentam a probabilidade da criança discriminar seus contextos, desenvolver repertórios e resolver problemas, o que contribui também para sua adaptação escolar.

Como forma de avançar nos estudos das relações entre as práticas educativas e o desempenho acadêmico, foi ainda objetivo deste estudo avaliar se as práticas educativas parentais poderiam predizer o rendimento acadêmico. Para tal análise, foi utilizado o método de regressão stepwise, ou seja, de forma aleatória, todas as práticas educativas (variáveis Independentes) do IEP foram testadas como preditoras do rendimento acadêmico (variáveis dependentes). Dessa forma, todas as práticas encontradas como preditoras do rendimento acadêmico deveram-se a relações significativas do ponto de vista estatístico. Os resultados podem ser observados na Tabela 3 .

Os resultados apontaram para coeficiente de determinação $\left(R^{2}\right)$ de 0,24 , ou seja, as práticas educativas parentais explicaram $24 \%$ da variância total das notas escolares, valores bastante significativos, em se tratando de comportamento multideterminado. Enquanto os coeficientes de regressão explicam a variância total, os coeficientes de regressão padronizados indicam a proporção em que as mudanças nas unidades de desvio padrão da variável preditiva afetam as mudanças no desvio padrão da variável dependente. Nos modelos de predição formulados na presente pesquisa, encontraram-se valores negativos e positivos de coeficiente de regressão padronizado representativos. Os coeficientes 
Tabela 3. Análise de regressão múltipla para rendimento acadêmico

\begin{tabular}{|c|c|c|c|c|c|c|c|}
\hline Variável Dependente & $\mathrm{R}^{2}$ & $F$ & Gl & $p$ & Variáveis Preditoras (IEP) & Beta padronizado & $\mathrm{P}$ \\
\hline \multirow{4}{*}{$\begin{array}{l}\text { Rendimento } \\
\text { acadêmico }\end{array}$} & \multirow{4}{*}{0,24} & \multirow{4}{*}{15,22} & \multirow{4}{*}{44} & \multirow{4}{*}{0,000} & Abuso físico mãe & $-0,242$ & 0,000 \\
\hline & & & & & Monitoria positiva mãe & 0,225 & 0,001 \\
\hline & & & & & Disciplina relaxada mãe & $-0,146$ & 0,034 \\
\hline & & & & & Disciplina relaxada pai & $-0,141$ & 0,038 \\
\hline
\end{tabular}

de regressão padronizados negativos referem-se à influência em sentido inverso da variável independente na dependente. Em suma, os resultados sugerem que quanto maior a monitoria positiva exercida pela mãe, e menor o uso de disciplina relaxada utilizada pelos pais, e baixa utilização de abuso físico materno, melhor o rendimento acadêmico da criança. Em geral, quase um quarto do rendimento acadêmico pode ser explicado pelas práticas utilizadas pelos pais.

No conjunto de práticas parentais selecionadas pelo modelo para predizer o rendimento acadêmico, a monitoria positiva foi a única prática educativa positiva. Essa prática contribui para um ambiente baseado no amor, no apoio e na confiança, sendo esse ambiente propicio para o bom desenvolvimento da criança e do adolescente e preventivo para comportamentos antissociais (Gomide, 2001; 2003; Sabbag \& Bolsoni-Silva, 2010; Salvo, 2010; Stattin \& Kerr, 2000).

Duas práticas negativas foram selecionadas pelo modelo. A prática do abuso físico se caracteriza por pais que utilizam de punição corporal para educar seus filhos, mesmo sem a intenção de causar lesão física ou moral (Gomide, 2004). O uso dessa prática leva à supressão do comportamento punido imediatamente, mas não ensina à criança outras formas de reagir e lidar com seus contextos. Assim, com repertório comportamental empobrecido, essas crianças muitas vezes apresentam dificuldades de lidar com situações difíceis por não saberem reagir de forma alternativa. É comum filhos de pais violentos também apresentarem comportamentos violentos (Bérgamo \& Bazon, 2011; Ceconello \& cols., 2003), o que pode levar a um déficit de habilidades sociais, que são essenciais na escola para manter boas relações com colegas e professores (Bolsoni-Silva \& Marturano, 2007; Camacho \& Matos, 2007; Leme \& Bolsoni-Silva, 2010) e que contribuirem para o desenvolvimento das dificuldades escolares. A disciplina relaxada caracteriza-se pela não manutenção de regras estabelecidas pelos pais, ou seja, regras não são cumpridas (Gomide, 2004; Salvo \& cols., 2005).
Aprender que as regras podem ser descumpridas em casa colabora para que as crianças e adolescentes aprendam a não seguir ordens em outros contextos, como a escola (Gomide, 2004).

Pesquisas (Camacho \& Matos, 2007; Cia \& cols., 2008; Garcia \& cols., 2009; McBride \& cols., 2005; Pereira \& cols., 2009; Salvador, 2007; Sapienza \& cols., 2009) corroboram o modelo preditivo observado no presente estudo. Observa-se que crianças e adolescentes com alto rendimento acadêmico estavam inseridos em famílias mais abertas e envolvidas, com mais diálogos e regras, e com menos abuso físico. Já entre aqueles que apresentavam baixo rendimento na escola, observou-se nas famílias maior uso de punição física e comunicação negativa entre pais e filhos. Filhos de pais que utilizam com muita frequência práticas de abuso físico e disciplina relaxada, além de falta de monitoria positiva, podem não aprender a cumprir regras e, assim, apresentar dificuldades em assumir responsabilidades na escola, com professores e colegas. Ainda, a alta frequência do uso das práticas de abuso físico no lar não contribui para que a criança desenvolva habilidades sociais que poderiam contribuir para suas relações na escola; são comuns filhos de pais abusivos desenvolverem repertórios de violência física como forma de resolver problemas. Tudo isso aliado a uma baixa monitoria positiva, ou seja, falta de acompanhamento caloroso e próximo, é contingência propícia para dificuldades de relações e de déficits de desenvolvimento que parecem contribuir para o baixo rendimento acadêmico.

\section{Considerações finais}

O objetivo deste estudo foi relacionar as práticas educativas parentais e o rendimento acadêmico em crianças e adolescentes. Foram encontradas correlações entre praticamente todas as práticas educativas maternas avaliadas e o rendimento acadêmico, indicando a importância da forma como a mãe contingencia os comportamentos do filho nesse período do 
desenvolvimento, o que reflete, em algum nível, em seu rendimento acadêmico. Quanto às práticas educativas paternas, foram as práticas negativas que em geral se correlacionaram, de forma inversa, com o rendimento acadêmico. Foi observada a importância da participação do casal parental para o desempenho acadêmico. Também, que pais de crianças com alto rendimento apresentaram mais práticas positivas e menos negativas quando comparadas a crianças com baixo rendimento.

Por fim, como forma de avançar nos estudos sobre as relações entre as práticas educativas e o desempenho acadêmico, foi analisada a possibilidade das práticas educativas parentais predizerem o rendimento acadêmico. Foi observado que, para crianças de idade entre 8 e 11 anos, existe influencia direta de três práticas educativas maternas e uma prática educativa paterna sobre o desempenho acadêmico. Os resultados encontrados apontam que as práticas maternas de monitoria positiva, disciplina relaxada, e abuso físico, além da prática educativa paterna de disciplina relaxada podem predizer quase um quarto do rendimento acadêmico, apoiando a hipótese da influência direta das formas utilizadas pelos pais na educação dos filhos também interferirem no rendimento acadêmico. Tais resultados apontam caminhos para a construção de programas de orientação a pais na escola, com objetivos de contribuir com os pais no acompanhamento das crianças, o que pode facilitar a melhora do desempenho escolar a partir da ação dos pais.

Entre as limitações do estudo, vale destacar o uso da percepção dos filhos sobre as práticas parentais, bem como os limites cognitivos e dificuldades de compreensão dos avaliandos, que podem ter influenciado os dados. E não foi uma variável discriminada no presente estudo a condição familiar da criança, ou seja, se esta vivia em família monoparental, nuclear, recomposta ou com outros cuidadores, fator este que pode ter interferido nos resultados. Para pesquisas futuras, seria importante o uso de delineamento envolvendo a avaliação da percepção de pais e filhos, além de aspectos contextuais dessas relações. Também se considera um limitador do presente estudo a utilização apenas do inventário de estilos parentais para avaliação das práticas educativas parentais, uma vez que medidas indiretas acabam por excluir elementos que podem ser cruciais para a compreensão das relações humanas.

De forma ampla, os resultados deste estudo apontam para novas possibilidades de atuação junto a crianças com baixo desempenho escolar. Trabalhos de orientação a pais, com foco nas práticas educativas de acompanhamento e regras, além de trabalhos buscando a diminuição da violência familiar, podem ser integrados às metodologias já existentes de trabalho com esse público.

\section{Referências}

Alvarenga, P., \& Piccinini, C. (2001). Práticas educativas maternas e problemas de comportamento em pré-escolares. Psicologia: Reflexão e Crítica, 14(3), 449-460.

Alvarenga, P., \& Piccinini, C. (2007). O impacto do temperamento infantil, da responsividade e das práticas educativas maternas nos problemas de externalização e na competência social da criança. Psicologia: Reflexão e Crítica, 20(2), 314-323.

Antunes, N. H., (2010). A parentalidade e a criança: estudo exploratório sobre a relação entre estilos parentais, sentido de competência parental e o comportamento da criança. (Dissertação de Mestrado), Faculdade de Psicologia e Ciências da Educação da Universidade de Coimbra, Coimbra, Portugal. Disponível em: http:// hdl.handle.net/10316/15400.

Beato, A. F. G., (2008). “Adolescer” entre relaçôes: parentalidade, amizade e amorosidade: que contributos na transição para a idade adulta. (Dissertação de Mestrado). Faculdade de Psicologia e Ciências da Educação da Universidade de Lisboa, Lisboa, Portugal. Disponível em: http://repositorio.ul.pt/ handle/10451/726.

Benetti, S. P. C., Pizetta, A., Schartwz C. B., Hass R. A., \& Melo, V. L. (2010). Problemas de saúde mental na adolescência: características familiares, eventos traumáticos e violência. Psico-USF, 15(3), 321-332.

Bergamo, L. P. D., \& Bazon, M. R. (2011). Abuso físico infantil: analisando o estresse parental e o apoio social. Psicologia: Teoria e Pesquisa, 27(1), 13-22.

Boas, A. C. V. B. V., \& Bolsoni-Silva, A. T. (2010). Habilidades sociais educativas de mães separadas e sua relação com o comportamento de pré-escolares. Psico-USF, 15(3), 75-92.

Boeckel, M. G., \& Sarriera, J. C. (2006). Estilos parentais, estilos atribucionais e bem-estar psicológico em jovens universitários. Revista Brasileira Crescimento e Desenvolvimento Humano, 16(3), 53-65.

Bolsoni-Silva, A. T., \& Marturano E. M. (2007). A qualidade da interação positiva e da consistência 
parental na sua relação com problemas de comportamentos de pré-escolares. Revista Interamericana de Psicología, 41(3), 349-358.

Bolsoni-Silva, A. T., \& Marturano E. M. (2010). Relacionamento conjugal, problemas de comportamento e habilidades sociais de pré-escolares. Psicologia: Teoria e Pesquisa, 26(1), 67-75.

Camacho, I., \& Matos, M. G. (2007). Práticas parentais educativas, fobia social e rendimento académico em adolescentes. Revista Brasileira de Terapia Cognitiva, 3(2), 37-55.

Ceconello, A. M., De Antoni, C., \& Koller, S. H. (2003). Práticas educativas, estilos parentais e abuso físico no contexto familiar. Psicologia em Estudo, 8 (número especial), 45-54.

Cia, F., D’Affonseca, S. M., \& Barham, E. J. (2004). A relação entre o envolvimento paterno e o desempenho acadêmico dos filhos. Paidéia (Ribeirão Preto), 14(29), 277-286.

Cia, F., Pamplin, R. C. de O., \& Del Prette, Z. A. P. (2006a). Comunicação e participação pais-filhos: correlação com habilidades sociais e problemas de comportamento dos filhos. Paidéia (Ribeirão Preto), 16(35), 395-406.

Cia, F. Pamplin R. C. O., Williams, L. C de A. (2008). O impacto do envolvimento parental no desempenho acadêmico de crianças escolares. Psicologia e estudo, 13 (2), 351-360.

Cia, E., Barham, E. J., \& Fontaine, A. M. G. V. (2010). Impactos de uma Intervenção com Pais: O Desempenho Acadêmico e Comportamento das Crianças na Escola. Psicologia: Reflexão e Crítica, 23(3), 533-543.

Cia, F., Pereira, C. S., Del Prette, Z.A.P., \& Del Prette A. (2006b). Habilidades sociais parentais e relacionamento entre pais e filhos. Psicologia em Estudo, 11(1), 73-81.

Costa, C. S. L., Cia, F., \& Barham, E. J. (2007). Envolvimento materno e desempenho acadêmico: comparando crianças residindo com a mãe e com ambos os pais. Psicologia Escolar e Educacional, 11(2), 339-351.

Garcia, S. C., Brino, R. F., \& Williams, L. C de A. (2009). Risco e resiliência em escolares: um estudo comparativo com múltiplos instrumentos. Psicologia $e$ Educaşão, 28(2), 23-50.
Gomide, P. I. C. (2001). Efeito das práticas educativas no desenvolvimento do comportamento anti-social. Psicologia Clínica e da Saúde, 10(2), 33-54.

Gomide, P. I. C. (2003). Estilos Parentais e comportamento anti-social. Em A. Del Prette \& Z. Del Prette (Eds), Habilidades sociais, desenvolvimento $e$ aprendizagem: questões conceituais, avaliação e intervenção (pp.21-60). Campinas: Alínea.

Gomide, P. I. C. (2004). Pais presentes, pais ausentes. (2 $2^{\mathrm{a}}$ ed.). Petrópolis: Vozes.

Gomide, P. I. C. (2006). Inventário de estilos parentais: modelo teórico, manual de aplicação, apuração e interpretação. (1 ${ }^{\mathrm{a}}$ ed.). Petrópolis: Vozes

Lila, T. F. B. V. (2009). Auto-estima e percepção das práticas parentais na fase final da adolescência. (Dissertação de Mestrado), Faculdade de Psicologia e Ciências da Educação da Universidade de Lisboa, Lisboa, Portugal. Disponível: http://repositorio.ul.pt/ handle/10451/900.

Loos, H., \& Cassemiro, L. F. K. (2010). Percepções sobre a qualidade da interação familiar e crenças auto-referenciadas em crianças. Estudos de Psicologia, 27(3), 293-303.

Martinho, L. V. F. (2010). O papel da educação parental no comportamento anti-social dos adolescentes. (Dissertação de Mestrado), Faculdade de Psicologia e Ciências da Educação da Universidade de Coimbra, Coimbra, Portugal. Disponível em: https://estudogeral. sib.uc.pt/handle/10316/14232.

McBride, B. A., Schoppe-Sullivan, S. J. (2005). Moon Ho The mediating role of fathers' school involvement on student achievement. Applied Developmental Psychology, 2(26), 201-216.

Moreira, L. V. C., \& Biasoli-Alves, Z. M. M. (2008). Práticas educativas: a participação da mãe e da criança na determinação das atividades da rotina diária. Revista Brasileira de Crescimento Desenvolvimento Humano, 18(1), 53-65.

Pereira, P. C., Santos, A. B., \& Williams, L. C. A. (2009). Desempenho escolar da criança vitimizada encaminhada ao fórum judicial. Psicologia Teoria e Pesquisa, 25(1), 19-28.

Reppold, C. T., \& Hutz, C. S. (2003). Reflexão social, controle percebido e motivações à adoção:Características psicossociais das mães adotivas. Estudos de Psicologia, 8(1), 25-36.

Psico-USF, Bragança Paulista, v. 19, n. 3, p. 511-521, set./dez. 2014 
Sabbag, G. M., Bolsoni-Silva, A. T. (2010). A relação das habilidades sociais educativas e das práticas educativas maternas com os problemas de comportamento em adolescentes. Estudo e Pesquisa em psicologia, 11(2), 423-441.

Salvador, A. P. V. (2007). A relação das práticas educativas parentais e o envolvimento com tarefas escolares, depressão e desempenho acadêmico em adolescentes, (Dissertação de Mestrado), Universidade Federal do Paraná, Curitiba, Brasil. Disponível em: http://www.ppge.ufpr. br/teses/M07_salvador.pdf.

Salvador, A. P. V. (2012). Intervenção em grupo com famílias na escola: foco nas queixas escolares dos filhos. (Tese de Doutorado), Universidade Federal do Paraná, Curitiba, Brasil. Disponível em: http://www. ppge.ufpr.br/teses/D12_Ana\%20Paula\%20Viezzer\%20Salvador.pdf.

Salvo, C. G. S., E. F. M., \& Toni, P. M. (2005). Práticas educativas como forma de predição de problemas de comportamento e competência social. Estudos de Psicologia, 22(2), 187-195.

Salvo, C. G. (2010). Práticas educativas parentais e comportamentos de proteção e risco à saúde na adolescência. (Tese de Doutorado), Instituto de Psicologia da Universidade de São Paulo, São Paulo, Brasil. Disponível: http:// www.teses.usp.br/teses/disponiveis/47/47133/ tde-30032010-141310/pt-br.php.

Sapienza, G., Aznar-Farias, M., \& Silvares, E. F. M. (2009). Competência social e práticas educativas parentais em adolescentes com alto e baixo rendimento acadêmico. Psicologia Reflexão e Critica, 22(2), 208-2013.

Sousa, C. S. G. R. (2009). A ansiedade social no jovem adulto - sua relação com os estilos parentais e com a vinculação na infância. (Dissertação de Mestrado). Instituto Universitário de Lisboa, Lisboa, Portugal. Disponível em: http://www. repositorioiul.iscte.pt/bitstream/10071/2108/1/ Disserta $\%$ C3\%A7\%C3\%A3o\%20de\%20Mestrado $\% 20(\mathrm{C} \% \mathrm{C} 3 \%$ A1 tia $\% 20$ Sousa).pdf.

Stattin, H., \& Kerr, M. (2000). Parental Monitoring: A Reinterpretation. Child Development, 71(4), 1072-1085.

Weber, L. N. D., Brandenburg, O.J., \& Viezzer, A. P. (2003). A relação entre o estilo parental e o otimismo da criança. Psico-USF, 8(1), 71-79.

Weber, L. N. D., Brandenburg, O. J., Viezzer, A. P. (2004). O uso de palmadas e surras como prática educativa. Estudo e psicologia, 9(2), 227-237.

Zamberlan, M. A. T., Ottoni, T. P. M. E., \& Sonego, R. V. (2005). Situações e recursos de aprendizagem em famílias de crianças escolares. Aletheia, 22, 71-78.

Recebido em: 08/10/2013

Reformulado em: 13/05/2014

Segunda reformulação em: 18/06/2014

Aprovado em: 18/07/2014

Sobre as autoras:

Caroline Guisantes de Salvo Toni é psicóloga, doutora em Psicologia Clínica, professora da Universidade Estadual Centro-Oeste, Irati-PR. Pesquisa as relações entre a família e a escola, com foco na promoção e prevenção de saúde.

Vanessa Aparecida Hecaveí é discente do curso de Psicologia da Universidade Estadual do Centro-Oestes, Irati-PR.

Contato com as autoras:

Caroline Guisantes de Salvo Toni

Caixa postal 106

CEP: 84500-000 Irati- PR

E-mail: carolineguisantes@yahoo.com.br

Psico-USF, Bragança Paulista, v. 19, n. 3, p. 511-521, set./deæ. 2014 
